\title{
The Influence of Interaction between Hydrophobic Stearate and Pozzolanic Additive on Hygric Transport and Storage Properties of Lime-based Plaster
}

\author{
Radka PERNICOVA ${ }^{1 *}$, Milena PAVLIKOVA ${ }^{2}$ \\ ${ }^{1}$ Czech Technical University in Prague, Klokner Institute, Solinova 7, Prague 6, 166 08, Czech Republic \\ ${ }^{2}$ Czech Technical University in Prague, Faculty of Civil Engineering, Thakurova 7, Prague 6, 160 00, Czech Republic \\ crossref http://dx.doi.org/10.5755/j01.ms.24.1.17876
}

Received 03 April 2017; accepted 23 June 2017

\begin{abstract}
In this paper water transport and storage parameters of hydrophobic plasters are studies. This article is focused on behavior of water and its degradation process inside of material matrix. Most of physic-chemical deteriorations of building materials are related to the penetration of moisture into building structure. For higher resistance of penetration water into materials, hydrophobic additions are used. Especially inner hydrophobic additive was applied to the interior structure to reduce destructive effect of water. Water storage parameters are slightly better for plaster without hydrophobisation. However, from the quantitative point of view the difference was not so important. Comparative measurements with pure lime-metakaolin plaster were done as well.

Keywords: hygric properties, hydrophobic additive, plaster, storage, transport.
\end{abstract}

\section{INTRODUCTION}

Most of the damage on building structures is directly related to the infiltration of moisture into building structures and material. Exterior layer of plaster should protect the building from these effects of external environment. Porous building materials can absorb a lot of water due to its porous structure, which may cause some negative effects on material. Water as a carrier medium has significant negative side effect. Transport of ions in direction away from construction could lead to leaching of the compounds and their subsequent efflorescence on the surface [1]. In the opposite direction, harmful substances such as chloride ions from de-icing salt may be carried into the material and therefore slightly damage its structure [2].

Hydrophobic additives are an important part of lime plaster. If hydrophobic admixture is added to plaster, hydrophilic part of molecule is connected to mineral structure while hydrophobic part is oriented outside the structure and can repulse water and therefore limit the water absorption. The hydrophobic principle increases surface tension together with contact angle of water due to formed hydrophobic layer on the inside surface of pore. Hydrophobic admixtures reduce pore walls wettability and replace capillary suction by capillary depression. Addition of hydrophobisation admixture to lime plaster leads to lower sorptivity and better resistance to water and aggressive solution penetration. Fatty acid salts, namely calcium or zinc stearate, are often used as a hydrophobisator [3].

This paper describes the principle of hydrophobicity as a function method for increases durability and service life of building materials. The article is about influence of inner hydrophobic additive on hygric properties of limepozzolana plaster. Specifically, the first part of the article

\footnotetext{
* Corresponding author. Tel.: +420-224-353513.

E-mail address: radka.pernicova@cvut.cz (R. Pernicova)
}

discusses the changes in the transportation of both liquid water and water vapour due to added hydrophobisation. The second part relates to the storage parameters for modified plaster in the form of sorption isotherms.

\section{EXPERIMENTAL DETAILS}

Mechanical destruction is most commonly caused by the action of withholding water, running water, rising ground water, and condensation. For this reason, it is necessary to know the material ability to absorb moisture [4]. Water transport was characterized in a quite common way using the sorptivity and apparent moisture diffusivity [5]. The wet cup method, dry cup method, and wet-dry combined method have been used in the measurements of the water vapour diffusion coefficient. The sorption isotherm and water retention curves have been measured for the description of water storage parameters. The sorption isotherms have been measured using the desiccators with different salt solutions in order to simulate specific relative humidities. The water retention curve has been determined using an ordinary pressure plate device [6].

\subsection{Materials and samples}

In this paper, three lime-based plasters have been studied. The first of them has hydrophobic and pozzolanic addition (denoted as HPP), the second one (denoted as PP) is with pozzolana but without hydrophobization. Pure lime plaster (denoted as P) has been prepared for comparative purposes. Metakaolin, a highly active pozzolanic material, has been used instead of lime as an alternative silicate binder. Metakaolin replaces $15 \%$ of lime by weight. The reason for using it is the supposed increase of compressive and flexural strength. Zinc stearate $\left[\mathrm{CH}_{3}\left(\mathrm{CH}_{2}\right)_{16} \mathrm{COO}\right]_{2} \mathrm{Zn}$ as the hydrophobic admixture for the lime-pozzolana plaster has been used to improve high values of hydric properties. The water/binder ratio has been modified 
according to mixture workability.

All plasters have been prepared in mass of ingredients: a binder (lime with/without metakaolin) and standardized sand in the ratio 1:3. Plaster mixtures have been prepared using laboratory mixing machine. Each mixture has been cast into a standard prism form; all prisms have been taken out of forms after two days and then cured for 28 days in an environment with high relative humidity.

Comparative measurements without any hydrophobic additives have been done as well. The test started 28 days after manufacture of sample had been made in order to allow enough time for hardening of the samples.

\subsection{Experimental measurements}

The measurement of basic parameters took place in a conditioned laboratory at the temperature of $22 \pm 1{ }^{\circ} \mathrm{C}$ and $25-30 \%$ relative humidity. Each result represents the average value from three to five measured values.

At first, basic properties of material have been measured. Bulk density $\rho_{b}\left(\mathrm{~kg} \mathrm{~m}^{-3}\right)$, matrix density $\rho_{m}\left(\mathrm{~kg} \mathrm{~m}^{-3}\right)$, mechanical properties $(\mathrm{MPa})$, and open porosity $\psi(\%)$ have been determined as fundamental characteristics of the physical material.

The simplest way how to describe liquid water transport through a porous material is realization of a onedimensional free imbibition experiment [7]. Samples with a size of $40 \times 40 \times 20 \mathrm{~mm}$ have been cut from the original prisms, water- and vapour-proof insulated with epoxy resin on four lateral sides, and then dried in an oven. The face side of each sample was immersed by $1-2 \mathrm{~mm}$ into water on top of a saturated sponge. The sample mass has been measured continuously. The water absorption coefficient $A$ $\left(\mathrm{kgm}^{-2} \mathrm{~s}^{-1 / 2}\right)$ has been calculated from the linear part of the dependence of tested sample mass increase on the square root of time. Then the apparent moisture diffusivity $\kappa\left(\mathrm{m}^{2} \mathrm{~s}^{-1}\right)$ has been calculated using the vacuum saturation moisture content $w_{\text {sat }}\left(\mathrm{kg} \mathrm{m}^{-3}\right)$ and water absorption coefficient [8].

Then the apparent moisture diffusivity has been calculated from the vacuum saturation moisture content and water absorption coefficient according to:

$\kappa_{a p p} \approx\left(\frac{A}{w_{s a t}-w_{0}}\right)^{2}$,

where $w_{\text {sat }}$ is the saturated moisture content and $w_{0}$ is the initial moisture content, $\mathrm{kg} \mathrm{m}^{-3}$.

The cup method has been used for determination of water vapour transmission properties. The measurement performed in this work has been based on the standard. The measurement has been carried out in steady state under isothermal conditions. It has been based on onedimensional water vapour diffusion and measuring the water vapour flux through the sample and partial water vapour pressure in the air under and above the surface of a specific sample. Water vapour transmission properties of a material have been obtained by placing a sample of the material on the top of a cup and sealing it. Two versions of the common cup method have been used in the measurements of the water vapour diffusion coefficient. For the first one, the sealed cup containing burnt $\mathrm{CaCl}_{2}$
( $0 \%$ relative humidity) has been placed in a controlled climatic chamber at $25 \pm 0.5^{\circ} \mathrm{C}$ and $25 \%$ relative humidity and it has been weighed periodically. For the second one, the cup containing saturated $\mathrm{K}_{2} \mathrm{SO}_{4}$ solution (97\% relative humidity) has been placed into $25 \pm 0.5^{\circ} \mathrm{C}$ and $25 \%$ relative humidity environment. At first, samples with a size of $100 \mathrm{~mm}$ in diameter and thickness of $20 \mathrm{~mm}$ have been cut from the standard prism $100 \times 100 \times 100 \mathrm{~mm}$ and water- and vapour-proof insulated with epoxy resin. Then the sealed cups with samples have been weighed periodically. The steady state values of mass increase or mass decrease have been used to determine the water vapour transfer properties. The diffusion coefficient of water vapour $D\left(\mathrm{~m}^{2} \mathrm{~s}^{-1}\right)$ and water vapour diffusion resistance factor $\mu$ have been determined in the practical calculations of water vapour transport parameters in porous buildings materials.

The water vapour diffusion coefficient $D\left(\mathrm{~m}^{2} \mathrm{~s}^{-1}\right)$ has been calculated from the data according to:

$D=\frac{\Delta m \cdot d \cdot R \cdot T}{S \cdot \tau \cdot M \cdot \Delta p_{p}}$,

where $\Delta m$ is the amount of water vapour diffused through the sample, $\mathrm{kg} ; d$ is the sample thickness, $\mathrm{m} ; S$ is the sample surface, $\mathrm{m}^{2} ; \tau$ is the period of time corresponding to the mass of water vapour $\Delta m$ transport, $\mathrm{s} ; \Delta p_{p}$ is the difference between partial water vapour pressure in the air under and above the surface of a specific sample, $\mathrm{Pa} ; R$ is the universal gas constant, $\mathrm{J} \mathrm{mol}^{-1} \mathrm{~K}^{-1} ; M$ is the molar mass of water, $\mathrm{kg} \mathrm{mol}^{-1} ; T$ is the absolute temperature, $\mathrm{K}$. On the basis of the diffusion coefficient, the water vapour diffusion resistance factor $\mu$ has been determined according to:

$\mu=\frac{D_{a}}{D}$,

where $D_{a}$ is the diffusion coefficient of water vapour in the air, $\mathrm{m}^{2} \mathrm{~s}^{-1}$ [9].

The main driving force of moisture transfer in hygroscopic area is the transport of water vapour. Moisture accumulation curve is known as sorption isotherm. It expresses the dependence of the moisture content in a material on the relative humidity of the surroundings [10]. Sorption isotherms have been measured using the desiccators with different salt solutions to simulate different values of relative humidity [11]. Dry material has been the initial state for all the measurements. The experiment has been performed concurrently in all desiccators in thermostatic chamber at $25{ }^{\circ} \mathrm{C}$. The water adsorption and desorption in a porous material are based on van der Waals forces between the surface of the porous matrix and water molecules. In the case of adsorption, the dry material mass increases after a contact with moist air because of gradual bonding of water molecules from the air to the pore walls [12]. This process stops at the moment when the equilibrium state between the water vapour pressure in the moist material and in the surrounding air is achieved. The mass of samples had been measured in specified periods of time until steady state value of mass has been achieved. Then the water content by volume $w$ 
has been calculated according:

$$
w=\frac{m_{s}-m_{0}}{V \cdot \rho_{w}},
$$

where $m_{s}$ is the mass of the wet sample in steady state conditions, $\mathrm{kg} ; m_{0}$ is the initial mass of the sample, $\mathrm{kg} ; \rho_{w}$ is the water density, $\mathrm{kg} \mathrm{m}^{-3}$ [13].

The moisture storage function is called the water retention curve in the overhygroscopic moisture range where liquid water transport is the dominant mode of moisture transfer. Classical methods of pressure plate device have been used for the principle of determination of water retention curve [14]. A capillary saturated sample of a porous material had been placed on a semi-permeable plate covered by a fine kaolin layer and a fine meshed cloth and it has been exposed to either underpressure under the plate or overpressure above the plate. Due to the pressure difference between the interior of the porous body and the surroundings, the porous plate either draws in water from the sample or transfers water into it, until pressure equilibrium is achieved [15]. At that moment the pressure in the porous space (i.e. the capillary pressure) is equal to the pressure in the measuring device which can be easily determined. The moisture content was measured by the gravimetric method, i.e. by weighing the sample before and after the process, or by measuring the volume of the drained or supplied water. After the measurements had been finished, the water content by volume $w$ of the sample has been calculated at each pressure level and a water retention curve was constructed as $w=w_{(p)}$ function using the measured $\left[p_{\mathrm{i}}, w_{\mathrm{i}}\right]$ points [16].

The sorption isotherm and the water retention curve for the same material can be unified into a general moisture storage function using the Kelvin relation, the relationship between the relative humidity and the capillary pressure $\mathrm{p}_{\mathrm{c}}$ in the pores at isothermal conditions:

$\varphi=\frac{p_{v}}{p_{v s}}=\exp \left(-\frac{p_{c}}{\rho_{l} R_{v} T}\right)$,

where $p_{v}$ is the water vapour pressure, $\mathrm{Pa} ; p_{v s}$ is the saturation vapour pressure, $\mathrm{Pa} ; \rho_{l}$ is the density of liquid water, $\mathrm{kg} \mathrm{m}^{-3} ; R_{v}$ is the gas constant of water vapour, $\mathrm{J} \mathrm{mol}^{-}$ ${ }^{1} \mathrm{~K}^{-1}$; and $T$ is the absolute temperature, $\mathrm{K} . p_{v s}$ can be obtained from Clausius-Clapeyron equation which links saturation vapour pressure with temperature, and $p_{c}$ which describes relation between capillary pressure and pore radius of the tube can be calculated from the YoungLaplace law:

$p_{c}=\frac{2 \sigma}{r} \cos (\theta)$.

Using Kelvin Act (5), Young-Laplace equation (6) physical process of capillary condensation may be expressed as geometrical dependence of the capillary pressure (relative humidity) in the pores of the characteristic pore sizes. Table 1 gives an overview of the relationship between capillary pressure and relative humidity pore sizes according to the Young-Laplace Kelvin equation.
Table 1. Relationship between capillary pressure, relative humidity and pore diameter

\begin{tabular}{|c|c|c|c|c|c|c|c|}
\hline \multicolumn{7}{|c|}{ Micro pores } & \multicolumn{5}{c|}{ Macro pores } \\
\hline $10^{-10}$ & $10^{-9}$ & $10^{-8}$ & $10^{-7}$ & $10^{-6}$ & $10^{-5}$ & $10^{-5}$ & $10^{-3}$ \\
\hline \multicolumn{7}{|c|}{ Pore diameter, $\mathrm{m}$} \\
\hline $10^{+4}$ & $10^{+3}$ & $10^{+2}$ & $10^{+1}$ & 1 & $10^{-1}$ & $10^{-2}$ \\
\hline \multicolumn{7}{|c|}{ Capillary pressure, bar } \\
\hline 0.05 & 0.6 & 0.93 & 0.99 \\
\hline \multicolumn{8}{|c|}{ Relative humidity } \\
\hline \multicolumn{8}{|c|}{ Retention curves } \\
\hline
\end{tabular}

\section{RESULTS AND DISCUSSION}

At first, basic properties as bulk and matrix density, open porosity, and flexural strength have been determined after 28 days. Results are shown in Table 2. The results shown are the average of three and more measured values. Special attention has been paid to measurements of porosity since it is one of the most important characteristics of the examined materials and significantly affects the shape and size of sorption and retention curves.

Table 2. Basic material properties

\begin{tabular}{|c|c|c|c|c|}
\hline No. & $\rho_{\mathrm{b}}, \mathrm{kg} \mathrm{m}^{-3}$ & $\rho_{\text {mat }}, \mathrm{kg} \mathrm{m}^{-3}$ & $\psi,{\mathrm{g} / \mathrm{m}^{2} \mathrm{~h}^{0,5}}$ & $\mathrm{f}_{\mathrm{cf}}, \mathrm{MPa}$ \\
\hline P & 1.650 & 2.605 & 36.7 & 0.26 \\
\hline PP & 1.695 & 2.620 & 35.4 & 1.90 \\
\hline HPP & 1.745 & 2.615 & 33.2 & 1.26 \\
\hline
\end{tabular}

Influence of hydrophobic additive on basic parameters has been negligible. The difference has been about a few percent. Hydrophobic plaster (HPP) has achieved lower open porosity and thus higher bulk density. Hydrophobic additive has decreased the strength of plaster by approximately about $30 \%$ due to interaction with metakaolin. Still, it remains at least 5 times higher than mechanical parameter of pure lime plaster.

The water vapour transport parameters of the studied plasters are presented in Table 3. Comparing the measured data of studied pozzolanic plasters, we can see very similar values of water vapour diffusion coefficients. Measured data of water vapour resistance factor show opposite behavior. For lower relative humidity, the value of HPP hydrophobic plaster is higher than the value of PP plaster. The difference is about $11 \%$. For higher relative humidity, value of HPP is only about $5 \%$ lower than PP. The accuracy of the measured results has been affected by temperature fluctuations during the experiment which can cause a measurement error of up to $\pm 10 \%$.

Table 3. Water vapour transport properties

\begin{tabular}{|c|c|c|}
\hline \multirow{2}{*}{ No. } & $D$ & $\mathrm{~m}^{2} \mathrm{~s}^{1}$ \\
\cline { 2 - 3 } & $97-25 \% \mathrm{RH}$ & $0-25 \% \mathrm{RH}$ \\
\hline P & $2.30 \mathrm{E}-6$ & $5.20 \mathrm{E}-6$ \\
\hline PP & $1.63 \mathrm{E}-6$ & $1.77 \mathrm{E}-6$ \\
\hline \multirow{2}{*}{ PPP } & $1.69 \mathrm{E}-6$ & $1.56 \mathrm{E}-6$ \\
\cline { 2 - 3 } & $\mu$ & - \\
\cline { 2 - 3 } & $97-25 \% \mathrm{RH}$ & $0-25 \% \mathrm{RH}$ \\
\hline P & 10.2 & 4.9 \\
\hline PP & 14.2 & 13.2 \\
\hline HPP & 13.7 & 14.8 \\
\hline
\end{tabular}


The values of liquid water parameters were in case of hydrophobic lime plaster HPP significantly lower than results obtained for pure lime plaster $\mathrm{P}$ and even for PP. This may be considered as a positive finding in general because the rain water could be transported slower into the load bearing structure. The results of water absorption coefficient and apparent moisture diffusivity are presented in Table 4. Measured values are mainly influenced by temperature and relative humidity fluctuations during the experiment, the relative measurement error is estimated to $\pm 5 \%$ of the measured value.

Table 4. Water liquid transport properties

\begin{tabular}{|c|c|c|c|}
\hline No. & $\mathrm{A}, \mathrm{kg} \mathrm{m}^{-2} \mathrm{~s}^{-1 / 2}$ & $\mathrm{~W}_{\mathrm{sat}}, \mathrm{kgm}^{-3}$ & $\kappa, \mathrm{m}^{2} \mathrm{~s}^{-1}$ \\
\hline $\mathrm{P}$ & $2.60 \mathrm{E}-1$ & 359.0 & $5.30 \mathrm{E}-7$ \\
\hline PP & $2.23 \mathrm{E}-1$ & 342.6 & $4.26 \mathrm{E}-7$ \\
\hline HPP & $6.53 \mathrm{E}-2$ & 332.4 & $3.87 \mathrm{E}-8$ \\
\hline
\end{tabular}

The results of measuring liquid water transport parameters in Fig. 1 show that the HPP material with lower porosity transported the liquid water in a much slower way than the PP material. Water absorption coefficient of HPP was $70 \%$ lower and the moisture diffusivity more than 10 times lower compared to PP.

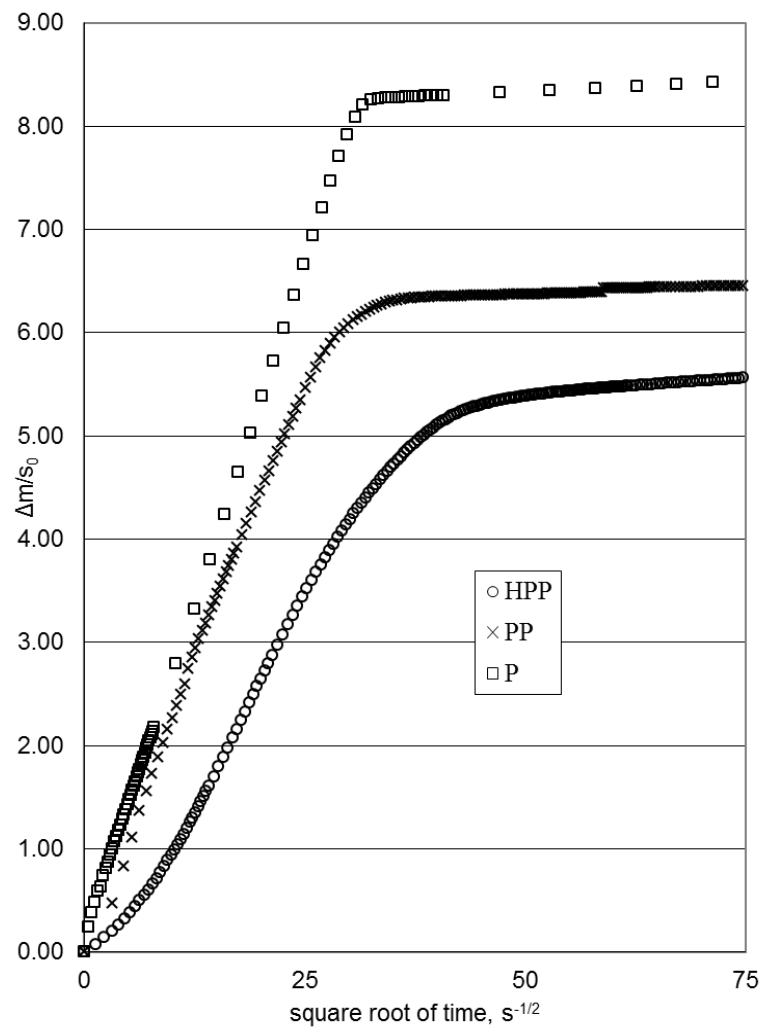

Fig. 1. Water liquid transport depending on time

For the both studied plasters with metakaolin, the obtained water storage parameters have been almost similar, taking the accuracy of measured method into account. Measurements of sorption and desorption isotherms have been carried out under constant conditions in a thermostatic chamber at a selected. However, it should be noted that the absolute measurement error can be up to $10 \%$.

If we compare the behavior of all tested materials, the sorption curves clearly show that the HPP is able to absorb more moisture than the PP at the fully sutured state. However, due to hydrophobic additive plaster HPP has slower absorption on the beginning of sorption curve. Desorption curves of PP and HPP are very similar. It is clear from the adsorption isotherms that the adsorption capacity of HPP, especially at relative humidity in range $75-95 \%$ is smaller. It means that hysteresis of PP is larger than HPP. The adsorption isotherms constructed from the measured points are shown at Fig. 2 [17].

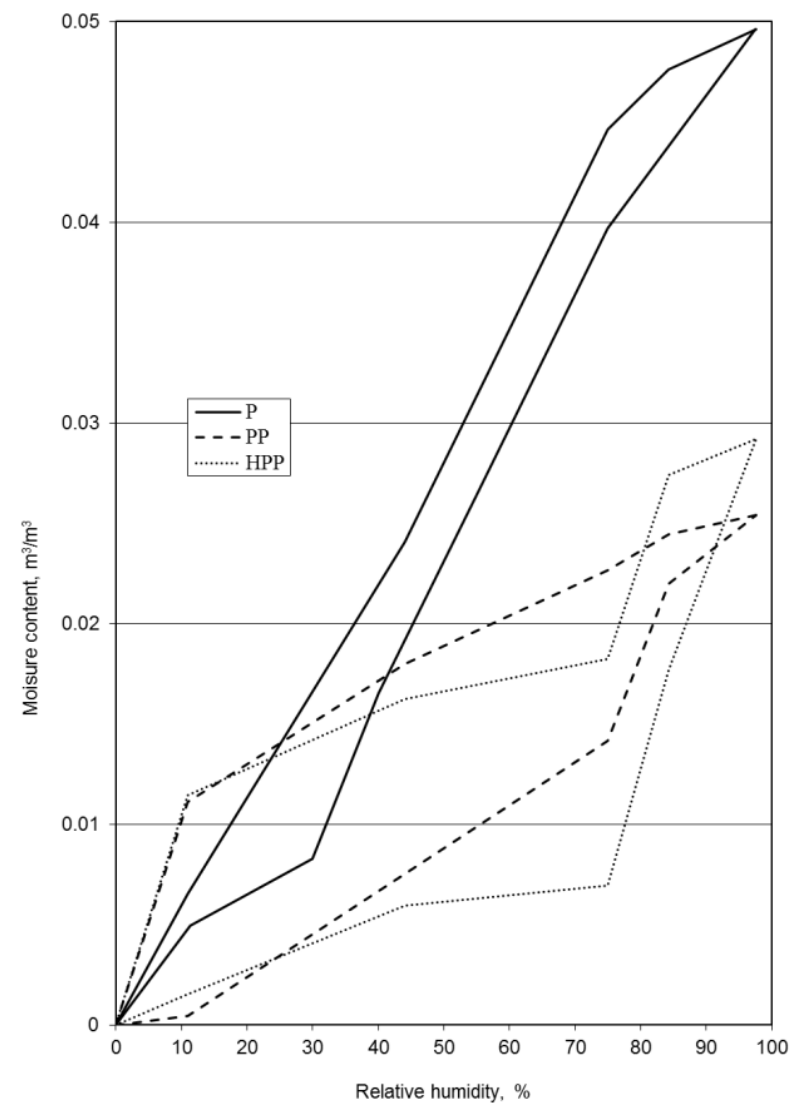

Fig. 2. Sorption and desorption isotherms of studied plasters

The HPP shows the steepest decline in moisture content with increasing pressure which has have characterized break by retention curve around 2-3 bars. The slower decline curve means the lower relative amount of capillary pores in the material. However, the open porosity of PP is higher, so plaster has to contend higher amount of larges pores. Fig. 3 clearly shows that HPP containing a large amount of capillary pores is able to absorb the most water.

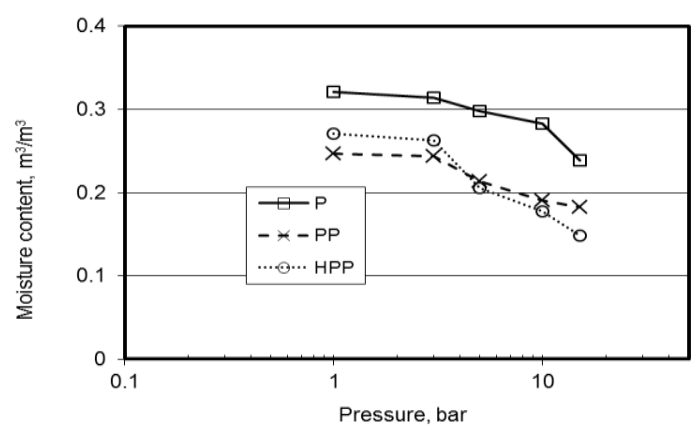

Fig. 3. Retention curve 
Different amounts of capillary pores in plaster have been created due to hydrophobic additive.

An experiment to measure the retention curves takes place in an air-conditioned laboratory at $25.0 \pm 2.0^{\circ} \mathrm{C}$ and $45 \%$ relative humidity and may take several months depending on the material selected. Although being affected by surrounding temperature and pressure fluctuations, the measurement error is only $2 \%$.

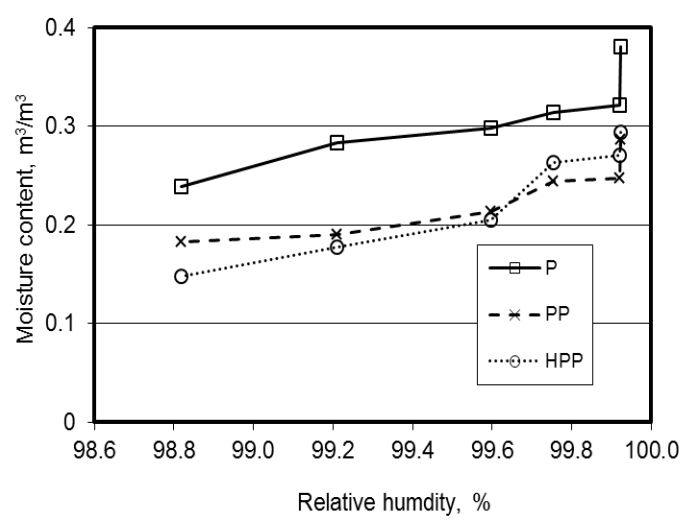

Fig. 4. Retention curve adapted into the desorption curves

Using the Kelvin equation that can be obtained from the measurement data of retention adapted into the desorption curves. Fig. 4 shows a water retention curves adapted into the desorption curves. PP with smaller number of small capillary pores has lower capacity.

Fig. 5 shows moisture accumulation curves for all investigated materials. Curve accumulation of moisture is one of the most important characteristics of a porous material. As you can see, hygroscopic and overhygroscopic curves are smoothly connected at both tested materials.

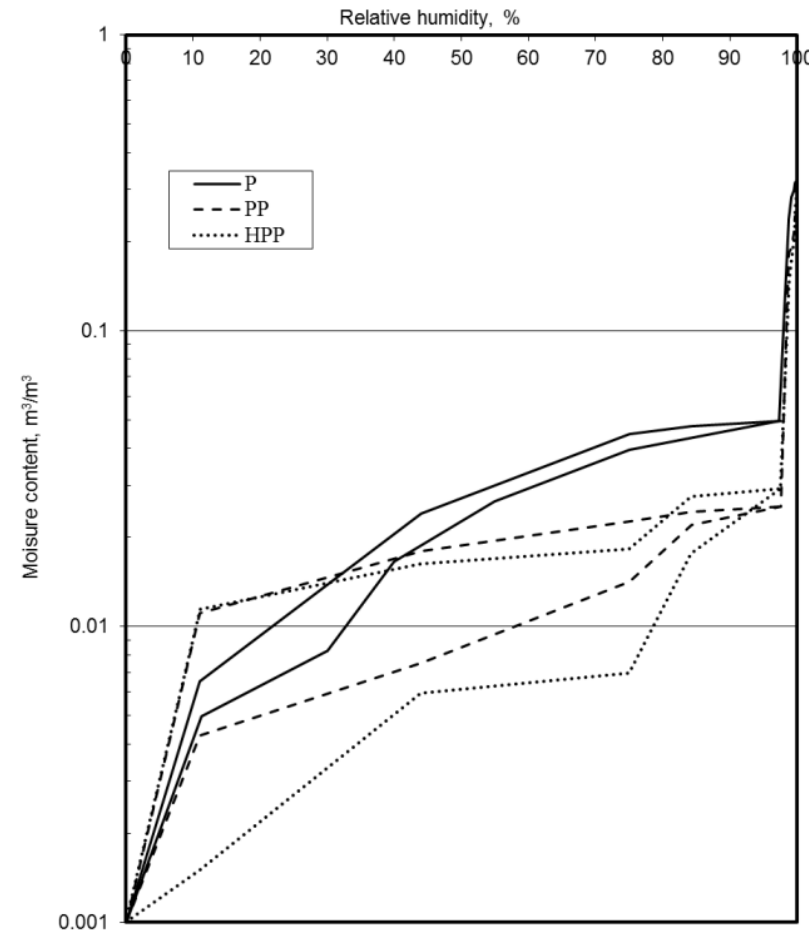

Fig. 5. Accumulation curves of tested materials

\section{CONCLUSIONS}

The hygric properties of hydro and non-hydrophobic plaster have been presented in this work. In many cases, significant damage is caused by moisture in the form of gas or liquid. Therefore, water transport and storage parameters are necessary for basic assessment of the behavior of these materials in construction.

Basic properties of both such plasters with metakaolin remained unchanged, so hydrophobic addition did not change properties of pozzolana plaster. Differences are within the variations in measurements.

There is a quite obvious difference in water liquid transport properties depending on hydrophobic addition. Especially moisture diffusivity of HP is more than ten times lower compared to pure lime-metakaolin plaster.

Analysis of measured samples has showed that open porosity decreases and more capillary pores are created by adding hydrophobic admixture. This is a negative effect such as a risk of damage due to ice formation. Open pore structures with large pores have enough free space for crystal growth so that crystallization does not lead to damage of internal structure. However, from the quantitative point of view, the differences were not very high so that this is only a minor flaw on otherwise significant improvement of hygric properties of tested material.

In future work, measurement of salt transport and storage properties of the designed lime-metakaolin plaster with and without hydrophobic admixture will be done.

\section{Acknowledgments}

This research has been supported by GACR Grant Agency of the Czech Republic No. GACR 15-10591S.

\section{REFERENCES}

1. Pernicova, R. Analysis of Formation and Testing of Efflorescence on Concrete Elements Advanced Materials Research 1025-1026 2014: pp. 641-644.

10.4028/www.scientific.net/AMR.1025-1026.641

2. Dhir, R.K., Jones, M.R, Ahmed, H.E.H. Determination of Total and Soluble Chlorides in Concrete Cement and Concrete Research 1990: pp. 579-590. https://doi.org/10.1016/0008-8846(90)90100-C

3. Pernicova, R., Ticha, P. Experimental Method of Measuring the Efficiency of Hydrophobic Surface Layer of Concrete. EAN 2016-54th International Conference on Experimental Stress Analysis 2016, ISBN: 978-802610624-1.

4. Robens, E., Benzler, B., Buchel, G., Reichert, H., Schumacher, K. Investigation of Characterizing Methods for the Microstructure of Cement Cement and Concrete Research 32 (1) 2002: pp. 87-90. https://doi.org/10.1016/S0008-8846(01)00633-0

5. Anderberg, A., Wadso, L. Method for Simultaneous Determination of Sorption Isotherms and Diffusivity of Cement-Based Materials Cement and Concrete Research 38 (1) 2008: pp. 89-94. https://doi.org/10.1016/j.cemconres.2007.08.023

6. Jirickova, M. Application of TDR Microprobes, Minitensiometry and Minihygrometry to the Determination 
of Moisture Transport and Moisture Storage Parameters of Building Materials CTU 2004: pp. 102.

7. Roels, S., Cameliet, J., Hens, H., Adan, O., Brocken, H., Černý, R., Pavlík, Z., Hall, C., Kumaran, K., Pel, L., Plagge, R. Interlaboratory Comparison of Hygric Properties of Porous Building Materials Journal of Thermal Envelope and Building Science 27 2004: pp. 307-325. https://doi.org/10.1177/1097196304042119

8. Kumaran, M.K. Report on Measurements to Determine Moisture Diffusivity of Eastern White Pine. IEA Annex XXIV Report T3-CA-92/04, 1994.

9. Kumaran, M.K. Moisture Diffusivity of Building Materials from Water Absorption Measurements, IEA Annex 24 Report T3-CA-94/01, Ottawa 1994.

10. Bergheim, S. Hygroscopic Material Properties, Water Vapour Permeability and Hygroscopic Sorption Curves for Materials Used in a Test House. Project Report, Norwegian Building Research Institute, Trondheim, 1998.

11. Johannesson, B., Janz, M. Test of Four Different Experimental Methods to Determine Sorption Isotherms Journal of Materials in Civil Engineering 14 (6) 2002: pp. $471-477$. https://doi.org/10.1061/(ASCE)0899-1561(2002)14:6(471)

12. Pavlik, Z., Zumar, J., Medved, I., Cerny, R. Water Vapor Adsorption in Porous Building Materials: Experimental
Measurement and Theoretical Analysis Porous Media 91 (3) 2012: pp. 939-954. https://doi.org/10.1007/s11242-011-9884-9

13. Kumar, A., Ketel, S., Vance, K., Oey, T., Neithalath, N., Sant, G. Water Vapor Sorption in Cementitious MaterialsMeasurement, Modeling and Interpretation Transport in Porous Media 103 (1) 2014: pp. 69-98. https://doi.org/10.1007/s11242-014-0288-5

14. Hansen, M.H. Retention Curves Measured Using Pressure Plate and Pressure Membrane Apparatus, Nordtest project 1267-96: 1997.

15. Hens, H., Carmeliet, J. Modelling Unsaturated Moisture Transport in Heterogeneous Limestone Katholieke Universiteit Leuven 2000: pp. 85-109.

16. Poyet, S., Trentin, K., Amblard, E. The Use of Sorption Balance for the Characterization of the Water Retention Curve of Cement-Based Materials Journal of Advanced Concrete Technology 14 (7) 2016: pp. 354-365. https://doi.org/10.3151/jact.14.354

17. Schiller, P., Wahab, M., Bier, Th., Waida, S., Mogel, H.J. Capillary Forces and Sorption Hysteresis of Cement Pastes with Small Slit Pores Procedia Materials Science 11 2015: pp. 649-654.

https://doi.org/10.1016/j.mspro.2015.11.010 